\title{
EL CONFLICTO DE CRIMEA COMO UN EPISODIO MÁS DE LA DIALÉCTICA TIERRA/MAR EN LA HISTORIA UNIVERSAL
}

\author{
The Conflict of Crimea as a New Episode of Land/See Dialectic in \\ Universal History ${ }^{1}$
}

Gerardo Tripolone ${ }^{2}$

\begin{abstract}
Sumario: 1 Introducción. 2 La historia universal es la historia de la lucha entre la tierra y el mar. 3 La tierra contraataca. $4 \mathrm{El}$ viejo derecho de gentes se impone al nuevo. Referencias
\end{abstract}

\begin{abstract}
Resumen: El presente trabajo aborda la anexión de Crimea por parte de Rusia a comienzos del 2014. Nuestro objetivo es probar un particular modo de interpretación de este acontecimiento a través del pensamiento de Carl Schmitt. Nuestra tesis es que, en clave schmittiana, el conflicto entre Rusia y la Otan puede ser comprendido como un resurgimiento de la lucha entre la Tierra y el Mar. El valor de esta interpretación radica en que posibilita comprender en todos sus alcances la problemática a la par que señala los defectos y desafíos del actual orden mundial.
\end{abstract}

Palabras claves: Crimea - Carl Schmitt - Ius Publicum Europaeum - Tierra/Mar

\begin{abstract}
This paper addresses the annexation of Crimea by Russia in 2014. Our aim is to test a particular way to understand this event through Carl Schmitt's thought. Our thesis is that, under the Schmittian point of view, the conflict between Russia and the NATO can be understood as a revival of the fight between Land and Sea. The value of our point of view is, first, the possibility to achieve a complete understanding of the conflict and, second, under our position we can show defects and challenges of actual world order.
\end{abstract}

Key words: Crime - Carl Schmitt - Ius Publicum Europaeum - Land/See

\section{INTRODUCCIÓN}

En un artículo del periódico británico The Guardian sobre el conflicto de Crimea y la reciente anexión rusa de este territorio ucraniano, Shaun Walker argumentaba que la visión ideológica de Putin es la de un "resurgimiento del poder conservador en oposición directa con la hegemonía geopolítica y los valores liberales de Occidente". 3 Por otro lado, en una entrevista otorgada por Dmitri Trenini al diario argentino Página/12, afirmó que la visión general que Europa tiene de Rusia es la de una "potencia del siglo XIX".4

\footnotetext{
${ }^{1}$ DOI deste artigo: http://dx.doi.org/10.12957/cosmopolitan.2014.10652.

${ }^{2}$ Consejo Nacional de Investigaciones Científicas y Técnicas, Argentina - Universidad Nacional de San Juan, Argentina.

3 WALKER, S. Ukraine and Crimea: what is Putin thinking?, The Guardian 25/03/2014: http://www.theguardian.com/world/2014/mar/23/ukraine-crimea-what-putin-thinkingrussia.

4 Entrevista realizada por Marcelo Justo, Página/12. Buenos Aires. 6/4/2014.
} 
Estas observaciones podrían ser tomadas como una argumentación peyorativa en contra de Rusia. Se establecería, por un lado, como "bueno" los valores liberales y modernos y, al contrario, como "malas" y "obsoletas" las razones "conservadoras" de una potencia decimonónica. Sin embargo, lo sepan o no Walker y Trenini, estas consideraciones entrañan un problema mucho más profundo que es bueno indagar. Eso que Walker llama "conservador" quizás sea, analizado bajo la perspectiva del pensamiento de Carl Schmitt, la visión clásica del Ius Publicum Europaeum que se extendió desde el siglo XVII hasta el final del "siglo largo" con la Primera Guerra Mundial, con lo cual, la calificación de Rusia como una "potencia del siglo XIX" quizás no sea tan errada.

Es esta intuición la que anima el presente trabajo. Bajo la óptica del pensamiento schmittiano, el actual conflicto geopolítico no implica, como se ha dicho, el resurgimiento de la Guerra Fría 5 o la oposición entre el derecho de autodeterminación y el de integridad territorial. ${ }^{6}$ Implica, más bien, una reedición de la dialéctica fundamental de la historia universal, es decir, la dialéctica entre la Tierra y el Mar.

En las páginas que siguen defenderemos una interpretación sobre la crisis de Crimea a partir de las reflexiones schmittianas sobre el orden mundial y el derecho internacional. No haremos una crítica del pensamiento schmittiano, cuestión que en lo referido al derecho internacional hemos abordado en otro lugar.7 Nuestro objetivo es utilizar las reflexiones de Carl Schmitt para defender la siguiente posición: la perspectiva rusa del problema de Crimea está anclada, de manera implícita pero evidente, en una visión clásica del derecho internacional. La legitimación jurídica de la anexión de este territorio se fundamenta en los parámetros del antiguo derecho de gentes, de base netamente terrestre, según lo describiera Carl Schmitt. A su vez, la oposición que recibió desde los países Occidentales a tal anexión, proviene de una argumentación que responde al actual paradigma del derecho internacional

\footnotetext{
5 WINTOUR, P. Russian actions over Ukraine may create new cold war - William Hague. The Guardian. Londres. 17/03/2014: http://www.theguardian.com/world/2014/mar/17/russianactions-ukraine-crimea-cold-war-william-hague.

${ }^{6}$ BAKER, P. Sovereignty vs. Self-Rule: Crime Reignites Battle. New York Times. 8/03/2014. http://www.nytimes.com/2014/03/o9/world/europe/crimea-crisis-revives-issue-of-secessionslegitimacy.html??version $=$ meter + at +5 \&region $=$ FixedCenter\&pgtype $=$ article\&priority $=$ true\&mo dule $=$ RegiWall-Regi\&action $=$ click\&_r $=0$

7 TRIPOLONE, G. La Doctrina de Carl Schmitt sobre el Derecho Internacional. Anuario Mexicano de Derecho Internacional. UNAM. Vol. XIV. 2014.
} 
que, siempre según el jurista alemán, es el propio de las potencias marítimas. Según Schmitt, este paradigma rechaza cualquier anexión territorial que se haga de forma expresa, permitiendo las intervenciones armadas sólo en caso de lucha por razones "humanitaria", que, en verdad, son guerras esencialmente discriminatorias.

Bajo parámetros schmittianos, el conflicto enfrenta a Rusia, potencia terrícola por excelencia y a la Unión Europea y los Estados Unidos, absolutamente entregados a la vida marítima. Este conflicto reedita una antigua dialéctica que Schmitt analizó como la base de la historia universal. Una vez más, el pensamiento del jurista alemán es buen orientador para entender los cambios del orden mundial. 1914 es la fecha del inicio de la Primera Guerra Mundial y es también el punto final del Ius Publicum Europaeum que hoy parece querer resurgir. Hasta principios de 2014, todos confiábamos en que, para bien o para mal, el progreso del orden internacional dirigía al mundo hacia la lógica cosmopolita e internacionalista propia de los valores liberales de las potencias Occidentales. Sin embargo, cuando creíamos que el paradigma basado en la tierra del Ius Publicum Europaeum estaba totalmente enterrado en las trincheras de la Gran Guerra, surgió con toda su fuerza la lógica propia de ese antiguo derecho de gentes a través de la postura política de Rusia en el escenario mundial.

Mucho más que una "vuelta" de Rusia como gran potencia mundial, lo que este conflicto nos está dejando es, en verdad, la muestra de que quizás Carl Schmitt no estaba errado cuando argumentaba que la tensión más importante es la tensión Tierra/Mar y no la que opone Occidente/Oriente ni Norte/Sur ni tampoco la antigua tensión entre Capitalismo/Comunismo.

Nuestro trabajo se desarrollará de la siguiente manera: en un primer momento analizaremos el pensamiento de Carl Schmitt sobre el derecho internacional bajo su propuesta histórico-filosófica, es decir, la de leer la historia a través de una eterna lucha entre el mar y la tierra, entre potencias marítimas y potencias terrestres. En un segundo momento, argumentaremos por qué esa lógica está siendo la guía del actual conflicto entre Rusia y los países Occidentales. Por último, probaremos que la estrategia de Putin y de Rusia en 
general, en el actual contexto mundial, se basa en un regreso a los parámetros del Ius Publicum Europaeum de base territorial.

\section{LA HISTORIA UNIVERSAL ES LA HISTORIA DE LA LUCHA ENTRE LA TIERRA Y EL MAR}

La tierra, dice Carl Schmitt al comienzo de Der Nomos der Erde, tiene una triple relación con el derecho y la justicia: contiene una medida de justicia (ya que sus frutos son la recompensa del trabajo); establece límites firmes (porque es susceptible de demarcación y división territorial) y, finalmente, es signo de un orden (porque manifiesta el "asentamiento de la convivencia humana" a través de la distribución espacial con vallados y cercados). ${ }^{8}$ En el mar no hay posibilidad de hacer estas divisiones. Los frutos extraídos de él son el producto del pillaje, la piratería y la guerra de botín. No hay ley ni ordenación ni hay límites jurídicos. La libertad del mar, originariamente, es libertad de botín. 9

En la obra de Schmitt, la lucha entre las potencias marítimas y las terrestres es lo que subyace en toda la historia de la comunidad internacional. ${ }^{10}$ La importancia de la lucha entre la tierra y el mar no es algo que se le haya ocurrido únicamente a nuestro autor. El jurista alemán más bien lo que hace es tomarlo para sí y aplicarlo a su pensamiento jurídico-político. De hecho, en el capítulo III de Tierra y mar, Schmitt argumenta que "el almirante Castex, dio a su libro sobre estrategia el título general El mar contra la tierra" lo cual, para el jurista alemán, constituía la continuación de "una gran tradición". ${ }^{11}$ Por otro lado, tampoco se puede decir que esta "gran tradición" la haya continuado exclusivamente Castex y Carl Schmitt, ya que geopolíticos de importancia fundamental como Halford Mackinder en 1904 veía "la lucha entre poderío

\footnotetext{
8 SCHMITT, C. Der Nomos der Erde im Völkerecht des Jus Publicum Europaeum. Berlin: Duncker \& Humblot, 1974, p. 13.

9 Ibid, pp. 13-14.

10 "Sobre las cimas de la historia universal se manifiestan las disputas de las potencias en lucha con una guerra de los elementos tierra y mar" (SCHMITT, C. La tensión planetaria entre Oriente y Occidente y la oposición entre tierra y mar. Revista de Estudios Políticos. Madrid. $\mathrm{N}^{\circ}$ 8, 1955, p. 8).

${ }^{11}$ SCHMITT, C. Tierra y mar. Consideraciones de la Historia Universal, trad. Rafael Fernández-Quintaniilla, en AGUILAR, H. O. (prólogo y selección de textos). Carl Schmitt, teólogo de la política, México: Fondo de Cultura Económica, 2004, p. 250.
} 
terrestre y poderío marítimo como un tema unificador de la historia". ${ }^{12}$ Dougherty y Pfaltzgraff señalan también la presencia de Geroges Liska como un autor que se dedicó al conflicto entre Estados continentales frente a los Estados marítimos en su libro de 1977 Quest for Equilibrium: American and the Balance of Power on Land and Sea. ${ }^{13}$

La distinción entre potencias marítimas y terrestres, para Schmitt, repercute en la configuración del derecho internacional y en las prácticas de la guerra. Para nuestro autor, las guerras que practican las potencias marítimas no tienen límites: las guerras navales son esencialmente totales. Las batallas marítimas, según Schmitt, no entienden de regulaciones y no separan civiles de militares. La guerra marítima no enfrenta militares contra militares, sino que ataca directamente a civiles cortando los suministros de las potencias terrestres. En Tierra y mar Schmitt recuerda la imagen mítica que los cabalistas judíos tenían de la historia: una lucha entre el Leviatán (una ballena, imagen de las potencias marítimas) y el Behemoth (un oso, imagen de las potencias terrestres). El Behemoth intenta destruir al Leviatán con sus colmillos y cuernos, mientras que el Leviatán asfixia el hocico del Behemoth con sus aletas. Para Schmitt, esta sería la "imagen mítica" del bloqueo naval de una potencia marítima a una terrestre. ${ }^{14}$

Lo propio del Leviatán, es decir, de las potencias marítimas, es asfixiar a las potencias terrestres y esperar su rendición, pero no luchando contra militares, sino cortando los recursos vitales de la población. Alemania no perdió la Primera Guerra Mundial en el frente terrestre, sino a causa de las penurias que la población tuvo que soportar durante cuatro inviernos a causa del bloqueo inglés y su consecuencia: la falta de suministros básicos. Indudablemente esto debió influir en la tesis de Carl Schmitt.

12 DOUGHeRTY, J. E.; PFALTZGRAFF, Robert L. Teorías en pugna en las relaciones internacionales. Trad. Cristina Piña. Buenos Aires: Grupo Editor Latinoamericano, 1993, p. 72. Según estos autores, Mackinder marca las derrotas de las potencias marítimas y la primacía de las terrestres a lo largo de la historia. En este punto se puede ver una distancia con lo que finalmente sucedió y con el pensamiento de Schmitt, quien veía el avance irremediable del mar que ganaba cada vez más batallas frente a la tierra.

13 Ibid, pp. 80-81.

14 SCHMITT, C. Tierra y mar..., loc. cit., pp. 350-351. Véase también SCHMITT, C. El Leviathan en la Teoría del Estado de Thomas Hobbes. Trad. Francisco Javier Conde. Granada: Comares, 2014, pp. 5-6. 
Además, la guerra marítima, para Schmitt, era guerra de botín, es decir, estaba dirigida contra la propiedad privada enemiga e "incluso neutral".15 Guerra de botín implica que el único objetivo es el pillaje, no la constitución de un nuevo orden. Sólo se busca afectar la propiedad, sustraerla sin más. La guerra es económica, afecta el comercio y las transacciones internacionales. Es por esto que las potencias marítimas, para Schmitt, no podían constituir un orden estable en el tiempo, a diferencia del Ius Publicum Europaeum de base terrestre y bajo la égida de la Europa continental.

El derecho de gentes del Ius Publicum Europaeum de base terrestre, buscaba mantener una ordenación internacional sustentable en el tiempo. El statu quo que debía sostenerse era el del equilibrio entre las potencias europeas, lo cual no impedía los cambios territoriales que no alterasen sustancialmente dicho equilibrio. En teoría, ningún Estado podía erigirse en dominador sobre los demás y todos juntos bregaban por el mantenimiento de ese equilibrio. ${ }^{16}$ Los nuevos Estados soberanos tenían un objetivo claro en las relaciones internacionales: mantener el equilibrio dentro de Europa haciendo que las desigualdades no sean lo suficientemente grandes como para alterar el orden jurídico internacional.

Ese equilibrio contrastaba con el desequilibrio entre Europa y América recientemente descubierta. Siendo un derecho internacional euro-céntrico, las potencias europeas tomaban al Nuevo Mundo como una tierra de nadie a conquistar, partir y dividir entre los Estados. Todo lo no europeo era ajeno a ese "equilibrio" y el territorio fuera de Europa era territorio libre para la conquista. Esta visión europea de superioridad (superioridad espiritual, diría Hegel y lo tomaría también Schmitt), al menos en parte, mantuvo cohesionada a Europa bajo el mismo régimen jurídico internacional. ${ }^{17}$

Esta cohesión no se perdía por las guerras entre naciones europeas, que estaban permitidas por el Ius Publicum Europaeum y que eran frecuentes. Estas guerras terrestres enfrentaban a potencias europeas por territorios e intereses europeos y también por el dominio de los territorios libres (todo lo no-europeo).

\footnotetext{
15 SCHMITT, C. Der Nomos der Erde..., loc. cit., p. 287.

${ }_{16}$ Véase no obstante la advertencia de CAMPDERRICH BRAVO, R. Derecho, política y orden internacional en la obra de Carl Schmitt (1919-1945). Barcelona: Universitat de Barcelona, 2003, p. 11 n. 29 y 30.

${ }^{17}$ SCHMITT, C. Tierra y mar..., loc. cit, p. 375.
} 
Sin embargo, estas batallas, según Schmitt, no hacían perder conciencia de lo común. La guerra era parte de las opciones que los Estados tenían para resolver sus conflictos, pero reconociendo los beligerantes la existencia política del enemigo y la imposibilidad de aniquilarlo.

Al menos hasta las guerras napoleónicas, en ninguna guerra se buscaba la aniquilación del enemigo, sino sólo imponer los intereses propios. Esta lógica se mantuvo también con la Restauración del Congreso de Viena de 1814 y duró cien años, hasta el estallido de la Gran Guerra. Esto era posible porque las guerras tenían, como dijimos, objetivos claros que se terminaban cuando se arribaban a ellos. En cambio, las guerras posteriores (ya en la época de Schmitt y más todavía en la nuestra) no tienen fines concretos, sino que buscan la aniquilación del enemigo que subvierte el orden político establecido, o, como dice Luigi Ferrajoli, el "orden/desorden mundial desigual, fundado en el dominio americano". 18

Bajo la perspectiva schmittiana, este orden-desorden es posible porque el derecho internacional está basado en la concepción del orden mundial propio de las potencias marítimas. El mar, como vimos al principio de este acápite, impide cualquier organización, a diferencia de la tierra. La lucha Tierra/Mar, en Schmitt, es la lucha entre el Orden y la Arbitrariedad. La Tierra es sinónimo de Orden y de Derecho. El Mar es sinónimo de Desorden y Arbitrariedad. La Tierra responde a los parámetros del Ius Publicum Europaeum, orden jurídicopolítico, según Carl Schmitt, claro y predecible, cuya finalidad era mantener la guerra entre potencias europeas acotada, evitando así la aniquilación.19

\section{LA TIERRA CONTRAATACA}

Mediante el acuerdo de Helsinki del año 1975 y el "memorándum de Budapest" de 1994, Moscú se obligó frente a Ucrania a respetarle la integridad territorial. Esas obligaciones parecen no ser óbice para que el líder ruso Vladimir Putin mantenga firme su postura tras anexar Crimea y, al momento de escribir estas líneas, no dé señales de cambiar el rumbo.

\footnotetext{
18 FERRAJOLI, L. Guerra y terrorismo internacional. Un análisis del lenguaje político. Anuario Mexicano de Derecho Internacional, México: UNAM. Vol. IX, 2009, pp. 24-25.

19 Hemos analizado esto en TRIPOLONE, G., op. cit. 
La violación al derecho internacional que supone no cumplir los tratados firmados, bajo la óptica de Carl Schmitt, no sería tal. Y no porque Schmitt llame a incumplir los pactos, ya que nada estaría más alejado de su concepción del orden mundial. Lo que sucede es que, para el jurista alemán, la ordenación de la tierra es superior a cualquier pacto o tratado: el orden del espacio terrestre es lo que da vida al derecho internacional y no a la inversa. El derecho internacional está en el orden concreto del espacio mundial, independientemente de lo que digan los tratados. El nomos de la tierra, es decir, la concreta distribución de los espacios terrestres, no depende de una ordenación positiva de tipo legalista formalizada en un tratado. El nomos es "la plena inmediatitud de una fuerza jurídica no atribuida por las leyes; es un acontecimiento histórico constitutivo, un acto de la legitimidad, que es el que da sentido a la legalidad de la mera ley". ${ }^{20}$

Más adelante agrega que

La verdadera base de esta ordenación de Derecho de Gentes no eran los compromisos precarios que contraían por sí mismas las voluntades soberanas, sino la pertenencia a un sistema de equilibrio espacial que era sentido como algo común. ${ }^{21}$

Primero está la ordenación espacial y ésta, en un momento posterior, dará sentido a la legalidad de los textos. La ordenación espacial es la fuente última de legitimidad jurídico-internacional y, por tanto, para que los tratados sean legítimos, tendrán que tomar en cuenta la legitimidad otorgada por la ordenación espacial. La inversa no se cumpliría, es decir, la ordenación internacional no obtiene su legitimidad de acuerdos o pactos internacionales.

En este sentido se entiende la argumentación de Rusia para anexar Crimea y la poca importancia que se le da a los tratados firmados por la Unión Soviética en 1975 y por la naciente Federación Rusa en 1994. Esos tratados que prohibieron la violación de la integridad territorial ucraniana, en la visión schmittiana del Ius Publicum Europaeum, no tendrían valor, ya que irían en contra de lo que el orden concreto de la tierra impone: Crimea, por su historia, su composición étnica y por el sentimiento de pertenencia del pueblo ruso (tanto el que vive en territorio ruso como aquellos que viven en Crimea), forma

${ }^{20}$ SCHMITT, C. Der Nomos der Erde..., loc. cit., p. 42.

${ }^{21}$ Ibid, p. 137 (cursivas nuestras). 
parte del Estado ruso. ${ }^{22}$ No se puede legitimar, bajo la óptica schmittiana, un cambio del orden terrestre mediante un tratado que no toma en cuenta el orden y las circunstancias concretas del territorio.

Esta es, justamente, la visión de Carl Schmitt del derecho. Frente a las dos posturas dominantes en la primera mitad del siglo XX, el normativismo y el decisionismo, el jurista le opone el "pensamiento del orden concreto":

La situación concreta [...] no es un presupuesto formal de la norma del que la Ciencia Jurídica pueda prescindir, sino un dato jurídico intrínseco para la vigencia de la norma y una determinación normativa de la norma misma. Una norma pura, sin referencia a una situación y a un tipo de hecho, sería un absurdo jurídico. ${ }^{23}$

La "novedad" de la teoría schmittiana es la toma de posición frente a la realidad como dato necesario del jurista. El derecho se compone también de la realidad de la vida, de lo concreto de la situación. No deben analizarse sólo las normas, ya que lo jurídico está también relacionado con la situación que regula y de la cual la norma emerge.

Sólo comprendiendo esto puede re-significarse la acusación de las potencias Occidentales sobre el supuesto incumplimiento del derecho internacional por parte de Rusia. La postura de Putin se entiende bien bajo la óptica schmittiana, ya que no sería tanto que Rusia incumpla el derecho, sino más bien que, siempre bajo la mirada de la teoría de Schmitt sobre el orden mundial (que parece ser la óptica jurídico-política de Putin), el derecho no estaba de acuerdo con la realidad concreta que pretendía estar regulado.

El politólogo Ignacio Sotelo afirma que "Los países occidentales apelan al derecho internacional para condenar la anexión, como si esto pudiera surtir el menor efecto". Basa su postura en que para las grandes potencias el "derecho internacional no juega el menor papel. Putin ha respondido con una larga lista de violaciones del derecho internacional, desde Irak, Kosovo a Libia, de los países de la OTAN". ${ }^{24}$ Este tipo de afirmaciones corresponden a una visión

\footnotetext{
${ }^{22}$ Más adelante veremos la argumentación de Putin al anexar Crimea, la cual se basó en que ese territorio sería "tierra santa rusa". Para el premier ruso, la convicción de pertenencia a Rusia ha sido siempre clara, basada en la "justicia y la verdad".

${ }^{23}$ SCHMITT, C. Sobre los tres modos de pensar la ciencia jurídica. Trad. Montserrat Herrero in: SCHMITT, C. Posiciones ante el Derecho. Madrid: Tecnos, 2012, p. 267.

${ }^{24}$ SOTELO, I. Occidente frente a Rusia. El País. Madrid. 31/3/2014 
escéptica del derecho internacional, según la cual el orden jurídico mundial de nada vale frente al poder y la fuerza. No es el momento de discutir aquí la verdad o falsedad de estas consideraciones. Lo que quisiéramos resaltar es que el punto de vista clásico que Rusia tiene del conflicto explica mejor la situación: no es tanto el fracaso del derecho internacional, sino la muestra de que otro derecho internacional es posible, independientemente de la valoración que sobre él tengamos. Porque, bajo la óptica de análisis de este trabajo, el conflicto no se limitaría al mero uso de la fuerza para violar el derecho internacional, sino al intento de hacer resurgir el antiguo Ius Publicum Europaeum de base terrestre.

Lo interesante de todo esto es que la óptica schmittiana (que, al ser una potencia terrestre, es la óptica de Rusia en estos momentos), permite comprender los fundamentos rusos de la anexión de Crimea, al tiempo que posibilita desarticular los argumentos de la OTAN. Los EEUU, la UE y las potencias Occidentales han pregonado un respeto al orden jurídico mundial que no parece ser tal, como deja sentado Sotelo. Las fundamentaciones que han esgrimido estos países para cometer las violaciones al orden internacional en Kosovo o Libia (por tomar dos casos), ha sido la protección humanitaria. Más allá de la discusión sobre la legalidad o no de las intervenciones de este tipo, vale decir que la doble vara con la que se manejan los Estados al tomar las decisiones (por caso, la contraposición entre el caso sirio y el libio) podría hacernos pensar que lo que prima es la pura arbitrariedad. ${ }^{25}$ Lo importante es notar que esta común impugnación al orden internacional es lo que, en parte, hace a Schmitt seguir insistiendo en la necesidad de un orden terrestre claro y predecible. Las ordenaciones terrestres tendrían esas características: Crimea perteneció, por la historia, por la cultura de su pueblo y por su ubicación geográfica, a Rusia, independientemente de argumentaciones humanitarias.

En definitiva, para una concepción antigua del derecho de gentes, no es necesario apelar a los circunloquios usados por las potencias Occidentales cada

http://internacional.elpais.com/internacional/2014/o3/31/actualidad/1396291415_150530.ht $\mathrm{ml}$

25 No es esta nuestra postura, como hemos argumentado en TRIPOLONE, G. ¿Es posible una Teoría Jurídica sobre la Aplicación de Normas Internacionales por el Consejo de Seguridad de Naciones Unidas?. Revista Electrónica de Estudios Internacionales. Madrid, $\mathrm{N}^{\circ} 26$, 2013. 
vez que buscan intervenir un Estado soberano. Rusia no necesitó criminalizar los líderes ucranianos, ni tratarlos de enemigos de la humanidad que forman parte de algún "eje del mal", como tuvo que hacer George W. Bush para atacar Irak y mantener la amenaza sobre Corea del Norte e Irán, entre otros "Estados canallas". A lo que apeló Rusia es a una concepción totalmente ajena al actual orden mundial, de ahí la inmediata sorpresa y reacción de la opinión pública.

\section{EL VIEJO DERECHO DE GENTES SE IMPONE AL NUEVO}

De los análisis políticos sobre la crisis de Crimea que hemos leído (por supuesto, no son ni un mínimo porcentaje de los que se han escrito en el mundo), uno de los que mejor parece comprender el conflicto es el de Celemens Wergin en el diario alemán Die Welt. El autor analiza la estrategia de Putin bajo la óptica de la Realpolitik heredera, según Wergin, de Maquiavelo y Thomas Hobbes. Esta estrategia se basaría en el "derecho de la fuerza", donde los intereses del más fuerte se imponen sobre el resto. Para Wergin, la Europa Occidental debe enfrentar a Putin pero no bajo fundamentos morales. ${ }^{26}$ Debe hacerlo en el terreno en que Putin está actuando, es decir, desde la Realpolitik, basándose en lo peligroso que para Alemania y el resto de Europa sería una desestabilización y un avance imperial de Rusia. ${ }^{27}$

Algo parecido piensa Thomas Friedman en su columna del 8 de abril en el New York Times. Friedman afirma que Putin pretende "jugar" en un terreno donde no hay reglas y, por tanto, para enfrentarlo, los EEUU deberían jugar ese mismo juego. Para "ayudar" a Ucrania y enfrentar a Putin, deberían colocarse también en el campo de las oposiciones fácticas y no en el del derecho internacional. Es por esto que el autor se pregunta si los EEUU están preparados para "jugar sucio". ${ }^{2} 8$

\footnotetext{
${ }^{26}$ Esta descripción, que puede ser desacertada o no, no es comparable a la tosquedad del senador y ex candidato republicano a la presidencia John McCain, quien habló de Putin como un político que vive en un mundo "brutal, cínico, donde el poder es adorado y el débil despreciado" (MCCAIN, J. Obama has make America look weak. New York Times. 14/3/2014, http://www.nytimes.com/2014/03/15/opinion/mccain-a-return-to-us-realism.html?_r=0).

27 WERGIN, C. Die verquere Realpolitik-Idee der Putin-Versteher. Die Welt. 6/4/2014. http://www.welt.de/debatte/kommentare/article126629930/Die-verquere-Realpolitik-Ideeder-Putin-Versteher.html.

${ }^{28}$ FRIEDMAN, T. Playing Hokey with Putin. New York Times. 8/4/2014. http://www.nytimes.com/2014/04/o9/opinion/friedman-playing-hockey-withputin.html?ref=opinion\&_r=o.
} 
Pueden sacarse varias conclusiones de estos textos. En primer lugar, que reconocen la existencia de una "nueva" forma de relaciones internacionales que sería el puro uso de la fuerza. A lo que Clemence Wergin llama "Realpolitik" y Thomas Friedman "juego sucio", debe oponerse una táctica similar, ya que el derecho internacional no parece alcanzar para "detener" el avance de Putin y "ayudar" a que Ucrania sea "libre" de Rusia (en el caso de Friedman) o, al menos y bajo una óptica realista, a mantener la estabilidad de Europa (bajo la mirada de Wergin). De cualquier forma, esto quiere significar que el actual derecho internacional se manifestaría incompetente para contraponerse a la fuerza del derecho de gentes clásico, a la lógica de la tierra del antiguo Ius Publicum Europaeum.

Ahora bien, ni Wergin ni Fiedman parecen querer admitir que no es la lógica de la pura fuerza la novedad en el actual conflicto. El poder y las razones de Estado nunca fueron algo ajeno al orden mundial, ni siquiera al posterior a la Carta de Naciones Unidas. La Realpolitik fue siempre, al menos en gran medida, el motor de las decisiones políticas internacionales. Lo novedoso en la crisis de Crimea, según intentamos probar, es que la lógica profunda que guía las decisiones de Rusia estaría anclada en el antiguo derecho de gentes que parecía haberse terminado con el comienzo de la Primera Guerra Mundial.

Por lo demás, es cierto que la decisión de Putin de anexar Crimea mediante el referéndum pudo haberse tomado de manera apresurada. ${ }^{29}$ También podría argumentarse que pudo haber tenido como punto disparador la decisión desde Kiev de eliminar la lengua rusa como idioma oficial en el Este de Ucrania..$^{30}$ Sin embargo, estas consideraciones no son óbice para afirmar que la lógica profunda que guío al gobierno de Moscú para tomar esta decisión es la propia del derecho de gentes clásico, contrapuesto al (y por tanto incomprendido por los cultores del) derecho internacional actual, de base marítima, siempre bajo el prisma schmittiano.

¿Qué valor tiene explicar la crisis todavía persistente bajo la mirada de Carl Schmitt? En lo absoluto buscamos justificar el accionar ruso ni tampoco querer endilgarle a Putin el adjetivo de "schmittiano" usado comúnmente de

29 MOSI, D. Putin el Grande. El País. 31/3/2014. http://elpais.com/elpais/2014/o3/28/opinion/1396008125_051546.html

30 ZAJEC, O. La obsesión anti-rusa. Le Monde diplomatique. Buenos Aires: Edición ConoSur, $\mathrm{n}^{\circ}$ 178, abril de 2014. 
forma despectiva. Lo que nos parece revelador del análisis es que, a partir de la obra de Carl Schmitt, es factible profundizar en la comprensión de la lógica rusa en la crisis de Crimea, al tiempo que levanta varias alarmas y llamados de atención al supuestamente consolidado orden internacional actual.

La confrontación que mantiene en vilo al mundo desde febrero de 2014, no es la lucha entre democracia y autoritarismo o entre libertad y despotismo. Occidente, como no se han cansado de señalar los analistas lúcidos, ha cometido demasiadas violaciones al derecho internacional como tener autoridad moral para señalar las actuales ilegalidades de Rusia. Sucede que ese no es el punto central de la controversia. La lucha no es por la legalidad sino por la legitimidad del orden mundial que, en el caso concreto como el actual, se manifiesta irreconciliable entre el Occidente marítimo y la Rusia terrestre.

Para las potencias de la OTAN, las intervenciones armadas (Kosovo, Irak, Libia, por tomar algunos ejemplos) y los cambios territoriales (Kosovo, por caso) deben hacerse siempre bajo el manto humanitario o democrático. Es por esto que intentan caricaturizar la imagen de Putin o, peor aún, colocarlo como la encarnación del mal, de la ambición por el poder y el despotismo. ${ }^{31}$ La lógica del actual derecho internacional les impide justificar su accionar en la "concreta ordenación del suelo", al estilo schmittiano o ruso. La estrategia de las potencias marítimas es la de colocar a ciertos gobiernos o Estados completos como enemigos incivilizados de la humanidad que deben ser aniquilados. ${ }^{2}$ Deben esconderse las reales ambiciones de dominio mundial y de expansión de su influencia a todo el globo.

Rusia, al contrario, mantiene de manera expresa sus fundamentos para anexar Crimea por razones territoriales y de orden concreto al estilo schmittiano. Crimea es "tierra santa rusa", dijo Putin, agregando que "siempre ha sido y seguirá siendo parte de Rusia. Esta convicción se basa en la verdad y

${ }^{31} \mathrm{El}$ analista y docente argentino Enrique Aschieri argumenta que el hecho de que se presente así al premier ruso, "no deja de ser una tontería más nacida de ese viejo empeño por presentar los acontecimientos para una fácil digestión como conflagraciones entre el bien y el mal. Es muy difícil, si no imposible, encontrar dónde puede haber 'bondad' en la arena internacional" (ASCHIERI, E. El juego del TEG. Cash. Suplemento de economía de Página/12. 13/4/2014).

${ }^{2}$ Esto lo había notado Schmitt mucho tiempo atrás en un texto de 1932 titulado "El imperialismo moderno en el derecho internacional público" (SCHMITT, C. Conceptos y posiciones en la guerra Weimar-Ginebra-Versalles. In: AGUILAR, H. O. Carl Schmitt, Teólogo de la política. México: Fondo de Cultura Económica, 2004, pp. 95-113). 
en la justicia y siempre ha sido clara y se ha pasado de una generación a otra. $\mathrm{Ni}$ el tiempo ni la circunstancias lo pueden borrar". 33

Es absolutamente revelador estas consideraciones de Putin sobre Crimea, ya que muestran que la argumentación rusa sobre su accionar está basada en esa convicción de pertenencia que "siempre ha sido clara". Es el orden terrestre, no los tratados, lo que funda el orden mundial. $\mathrm{Y}$ es la pertenencia territorial, étnica e histórica, lo que hace que Crimea sea rusa. Los tratados podrán decir otra cosa, pero eso no se condice con la concreta ordenación. El paralelismo con la teoría schmittiana del derecho internacional basada en la ordenación terrestre y que no embebe su fuerza de los tratados, es más que evidente.

Además, Putin mantiene con total evidencia que lo que está en juego es su dominio geopolítico en su zona de influencia y es por esto que decidió "ponerle límites" a Occidente que "pretende arrinconarnos", según las expresiones usadas por el premier ruso. 34 Porque si bien en un primer momento de la crisis utilizó como argumento de la infiltración militar la "protección de ciudadanos rusos", en última instancia -es decir, cuando se hizo el referéndum y se tuvo que dar explicaciones-, Putin justificó la anexión de Crimea no por razones "humanitarias" ni de protección de civiles. La anexión se basó en la concreta ordenación territorial que indicaría que Crimea es parte integral de Rusia, sin obviar la búsqueda de frenar el avance de la OTAN en las inmediaciones de la potencia euroasiática. Estas claves se tornan más comprensibles bajo el pensamiento de Carl Schmitt.

Es por demás claro que un mundo regido por cualquiera de las dos lógicas será siempre un mundo en peligro y arbitrario para con los países no detentores de poder militar. Los países periféricos sólo contemplamos las luchas entre dos polos de poder que se baten por definir cómo se estructurará el orden mundial, sin tomar en cuenta qué dice la abrumadora mayoría de los Estados en el mundo. El diagnóstico de Donoso Cortés, elaborado 1847, parece tener

\footnotetext{
33 Ver: http://internacional.elpais.com/internacional/2014/o3/18/actualidad/1395125826_ 603105.html

34 LEE, P. Las razones de Rusia detrás de la anexión de Crimea. El País. 23/3/2014.

http://www.elpais.com.co/elpais/internacional/noticias/razones-rusas-detras-anexion-crimea
}

Revista de Direito Internacional do Programa de Pós-Graduação em Direito da UERJ 
actualidad: sólo los Estados Unidos, Inglaterra y Rusia pueden permitirse eso que llamamos "política exterior". $35 \mathrm{El}$ resto se adapta a sus paradigmas.

Es este persistente peligro lo que lleva a que, a pesar de que se pregona la paz, el desarme y la convivencia entre naciones, las grandes y medianas potencias continúan armándose e invirtiendo ingentes recursos en preparar sus ejércitos para guerras que supuestamente no existirían. Lo que la crisis de Crimea aporta como novedoso es que la lucha entre la Tierra y el Mar ha resurgido y el antiguo derecho de gentes parece querer emerger luego de cien años de ocultamiento. Al imperialismo marítimo vestido en ropajes humanitarios de Occidente, nuevamente se le opone un imperialismo de base terrestre y clásica.

\section{REFERENCIAS}

ASCHIERI, E. El juego del TEG. Cash. Suplemento de economía de Página/12. 13/4/2014.

BAKER, P. Sovereignty vs. Self-Rule: Crime Reignites Battle. New York Times. 8/03/2014.

CAMPDERRICH BRAVO, R. Derecho, política y orden internacional en la obra de Carl Schmitt (1919-1945). Barcelona: Universitat de Barcelona, 2003.

DOUGHERTY, J. E.; PFALTZGRAFF, Robert L. Teorías en pugna en las relaciones internacionales. Trad. Cristina Piña. Buenos Aires: Grupo Editor Latinoamericano, 1993.

FERRAJOLI, L. Guerra y terrorismo internacional. Un análisis del lenguaje político. Anuario Mexicano de Derecho Internacional, México: UNAM. Vol. IX, 2009.

FRIEDMAN, T. Playing Hokey with Putin. New York Times. 8/4/2014.

MCCAIN, J. Obama has make America look weak. New York Times. 14/3/2014.

MOSI, D. Putin el Grande. El País. 31/3/2014.

SCHMITT, C. Conceptos y posiciones en la guerra Weimar-GinebraVersalles. In: AGUILAR, H. O. Carl Schmitt, Teólogo de la política. México: Fondo de Cultura Económica, 2004.

SCHMITT, C. Der Nomos der Erde im Völkerecht des Jus Publicum Europaeum. Berlin: Duncker \& Humblot, 1974.

${ }_{35}$ Citado en SCHMITT, C. Interpretación europea de Donoso Cortés. In: AGUILAR, H. Carl Schmitt, teólogo de la política. México: Fondo de Cultura Económica, 2004, p. 231. 
SCHMITT, C. El Leviathan en la Teoría del Estado de Thomas Hobbes. Trad. Francisco Javier Conde. Granada: Comares, 2014.

SCHMITT, C. La tensión planetaria entre Oriente y Occidente y la oposición entre tierra y mar. Revista de Estudios Políticos. Madrid. Nº 8, 1955.

SCHMITT, C. Sobre los tres modos de pensar la ciencia jurídica. Trad. Montserrat Herrero. In: SCHMITT, C. Posiciones ante el Derecho. Madrid: Tecnos, 2012.

SCHMITT, C. Tierra y mar. Consideraciones de la Historia Universal, trad. Rafael Fernández-Quintaniilla. In: AGUILAR, H. O. (prólogo y selección de textos). Carl Schmitt, teólogo de la política, México: Fondo de Cultura Económica, 2004.

SCHMITT, C. Interpretación europea de Donoso Cortés. In: AGUILAR, H. Carl Schmitt, teólogo de la política. México: Fondo de Cultura Económica, 2004

SOTELO, I. Occidente frente a Rusia. El País. Madrid. 31/3/2014.

TRIPOLONE, G. La Doctrina de Carl Schmitt sobre el Derecho Internacional. Anuario Mexicano de Derecho Internacional. UNAM. Vol. XIV. 2014.

WALKER, S. Ukraine and Crimea: what is Putin thinking? The Guardian 25/03/2014.

WERGIN, C. Die verquere Realpolitik-Idee der Putin-Versteher. Die Welt. 6/4/2014.

WINTOUR, P. Russian actions over Ukraine may create new cold war - William Hague. The Guardian. Londres. 17/03/2014.

ZAJEC, O. La obsesión anti-rusa. Le Monde diplomatique. Buenos Aires: Edición Cono-Sur, $\mathrm{n}^{\circ}$ 178, abril de 2014. 